\title{
BMJ Open Association of maternal socioeconomic status and race with risk of congenital heart disease: a population-based retrospective cohort study in Ontario, Canada
}

\author{
Qun Miao (D) , 1,2,3 Sandra Dunn (1) , ${ }^{1,4,5}$ Shi Wu Wen (1) ,2,5,6 Jane Lougheed, ${ }^{7,8}$ \\ Cynthia Maxwell (D) , 9,10 Jessica Reszel (D) , ${ }^{1,4,11}$ Kaamel Hafizi, ${ }^{1}$ Mark Walker ${ }^{1,2,5,6}$
}

To cite: Miao Q, Dunn S, Wen SW, et al. Association of maternal socioeconomic status and race with risk of congenital heart disease: a populationbased retrospective cohort study in Ontario, Canada. BMJ Open 2022;12:e051020. doi:10.1136/ bmjopen-2021-051020

- Prepublication history and additional supplemental material for this paper are available online. To view these files, please visit the journal online (http://dx.doi.org/10.1136/ bmjopen-2021-051020).

Received 10 March 2021 Accepted 05 January 2022

Check for updates

(C) Author(s) (or their employer(s)) 2022. Re-use permitted under CC BY-NC. No commercial re-use. See rights and permissions. Published by BMJ.

For numbered affiliations see end of article.

Correspondence to

Dr Qun Miao;

gmiao@bornontario.ca

\section{ABSTRACT}

Objective To investigate the interrelationships between maternal socioeconomic status (SES), race and congenital heart diseases (CHD) among infants.

Design Retrospective cohort study.

Study setting Ontario, Canada.

Study population All singleton stillbirths and live births born in hospitals between 1 April 2012 and 31 March 2018 in Ontario, Canada ( $n=804$ 292).

Outcome CHD.

Analysis Multivariable logistic regression models were performed to assess associations between maternal neighbourhood household income, education level, race and CHD while adjusting for maternal age at birth, assisted reproductive technology, obesity, pre-existing health conditions, substance use during pregnancy, maternal rural residence and infant's sex.

Results Compared with infants whose mothers lived in the highest median household income neighbourhoods, infants whose mothers lived in the lowest median income neighbourhoods had a higher likelihood of having CHD (adjusted OR 1.15, 95\% Cl 1.06 to 1.24). Compared with infants whose mothers lived in neighbourhoods with more people with a university or higher degree, those infants whose mothers lived in neighbourhoods with less people with a university or higher degree had a higher chance of developing CHD (adjusted OR 1.26, 95\% $\mathrm{Cl} 1.16$ to 1.36). Compared with white mothers, black mothers had a higher odds of giving birth to a child with CHD (adjusted OR $1.40,95 \% \mathrm{Cl} 1.27$ to 1.54). No association was detected between White and Asian mothers and CHD among infants. Conclusions Our study indicates that there are inequities in CHD burden by maternal SES and race in Ontario, Canada. Further investigation is needed to examine racial variation in $\mathrm{CHD}$ using more detailed ethnic data.

\section{INTRODUCTION}

Congenital heart disease (CHD) is a significant cause of infant morbidity and mortality. ${ }^{1}$

${ }^{2}$ CHD accounts for $30 \%-45 \%$ of all congenital anomalies and accounts for over one-third of infant deaths due to congenital anomalies
Strengths and limitations of this study

- Median household income and the percentage of people with a university or higher degree to estimate maternal socioeconomic status status at the maternal dissemination area (DA) level.

- The race of the mother was captured from the prenatal screening dataset in Ontario, Canada.

- Using population-based data to examine the complex relationships between community-level household income and education level, the pregnant person's race and congenital heart disease (CHD) after taking into account confounders present in the Canadian context.

- Further investigation is needed to examine racial variation in $\mathrm{CHD}$ using more detailed ethnic data.

in North America ${ }^{1-3}$. Global prevalence rates for CHD are estimated at 3.7-17.5 cases per 1000 births. $^{1-4}$ In comparison, CHD prevalence in Canada has been estimated at 12.3 cases per 1000 births. ${ }^{4}$

It has been reported that certain factors are associated with CHD including parental history of CHD, advanced reproductive age, infection, environmental exposures, pre-pregnancy risk factors such as obesity, diabetes, assisted reproductive technology (ART), medications, substance and alcohol use, genetic factors, and infant sex. ${ }^{3-7}$ In addition, numerous studies have shown that CHD is associated with parental socioeconomic status (SES).${ }^{89}$ We previously reported the impact of maternal SES on the risk of CHD using a number of neighbourhood SES indicators and found low household income, poverty, lower maternal education level and unemployment are associated with CHD. ${ }^{10}$ These findings suggest inequities in maternal and child health in Ontario, 
Canada. ${ }^{10}$ Furthermore, limited data suggest maternal race may also play an important role. ${ }^{11} 12$ One national population-based study including 5350 infants with CHD in the UK reported that Asian and black populations were at a higher risk of overall CHD than those in the white group. ${ }^{13}$ This group noted that the non-white populations resided in disadvantaged neighbourhoods. ${ }^{13}$ Another study including 8029 singleton infants with CHD in the USA found racial differences in certain CHD types. ${ }^{14}$

It is unknown whether race is an independent risk factor for CHD, reflecting historical patterns of adverse health outcomes and lower SES. Studies examining the relationship between race and CHD in Canada is perhaps distinct from other parts of the world due to the diversity of its population, largely through immigration. ${ }^{13-15}$ Simultaneously, racial poverty is rising among certain minority groups in Canada. ${ }^{16}$ Health equity research, specifically related to prenatal care and CHD in Canada, is lacking. ${ }^{17}$ Therefore, we conducted a study to examine the interrelationships between maternal SES, race, and CHD among infants using population data from the province of Ontario, Canada.

\section{METHODS}

This study was one part of a larger study on SES and CHD. ${ }^{10}$ The title is "Neighbourhood maternal socioeconomic status indicators and risk of congenital heart disease'. Here, we summarise our methods, which were previously reported. ${ }^{10}$

\section{Study design, setting and study population}

This was a population-based retrospective cohort study. The cohort included singleton births (live births and still births) that occurred in Ontario hospitals (birthweight $\geq 500$ grams or gestational age $\geq 20$ weeks), as well as late stage pregnancy terminations (terminated at gestational age $\geq 20$ weeks or birthweight $\geq 500 \mathrm{~g}$ ) from 1 April 2012 to 31 March 2018. We excluded records where the pregnant individuals resided outside of Ontario.

\section{Data sources}

As a prescribed registry, the Better Outcomes Registry \& Network (BORN) Ontario collects data on every birth in Ontario. ${ }^{1819}$ The database, called the BORN Information System (BIS), includes many important data elements, such as maternal demographic characteristics and health behaviours; pre-existing mental health problems; obstetric complications; prenatal screening; intrapartum interventions; fetal and newborn anomalies; birth outcomes; and other data from labour, birth and postpartum stages. ${ }^{10}$ The data are collected by encounters, but also aggregated into maternal pregnancy and infant datasets. ${ }^{1018-22}$ Our analysis used multiple datasets from the BIS including: aggregate pregnancy, aggregate infant, antenatal specialty (AS) for high-risk pregnant individuals, prenatal screening, and prenatal screening follow-up (PSFU) data. High-quality data are maintained in the BIS through in depth training for data entry personnel, ongoing data validation and quality checks. ${ }^{10}$ 18-22

The Canadian Institute for Health Information (CIHI) maintains the Discharge Abstract Database (DAD) and the National Ambulatory Care Reporting System (NACRS), which BORN receives data from on an annual basis. $^{23}$ These CIHI data include maternal, newborn, and child (up to 1 year of age) records from acute care and emergency facilities in Ontario. ${ }^{23}$ We used this CIHI data together with data from the BIS to identify infants (up to age 1 year) who had a diagnosis of CHD in hospitals.

The 2016 Canadian Census and Postal Code Conversion File Plus (PCCF+) version 7B: Statistics Canada and Canada Post collaboratively developed PCCF+ that contains postal codes matched with dissemination areas (DA), from the latest Canada-wide 2016 Census data. $^{23}$ By linking the PCCF+ and the Census data to the study cohort using maternal residence postal codes, we obtained maternal neighbourhood median household income and education at a DA level.

\section{Data linkages}

We first obtained the baseline study population from the aggregate infant dataset in the BIS. We then linked multiple data sources to obtain SES and race variables (exposures) and the outcome of CHD, and covariates (please see the data linkage flow chart in online supplemental appendix A).

\section{Exposures}

At the maternal DA level, we used median household income to estimate family income and the percentage of people aged 25-64 with a university or higher degree to estimate maternal education level, which were obtained from the 2016 Census and categorised into quintiles [quintile 1 (Q1) - quintile 5 (Q5)].

The race of the mother was captured from the prenatal screening dataset in the BIS. Race categories were predefined on the prenatal screening requisition forms including 'white', 'Asian', 'black', 'Indigenous people', 'Others' and 'Unknown (non-prenatal screening)'. Due to the privacy policy for Indigenous people in Canada, we combined Indigenous people into the 'Others' category. The 'Others' group also included individuals who were of mixed races. In our study cohort, around $65 \%$ of pregnant individuals participated in prenatal screening tests, and most of these individuals had complete race data entered on their screening requisition form $(>99 \%)$. Approximately $35 \%$ of individuals in this birth cohort did not participate in prenatal screening, therefore, we were not able to identify these pregnant people's race; these subjects are included in the 'Unknown' group. ${ }^{25}$

\section{Outcomes}

We linked the baseline cohort to the BIS data (AS and prenatal screening follow-up) and CIHI data (DAD and NACRS) to obtain CHD cases. Specifically, we used the BIS to identify fetal and newborn CHD cases from the 
anomaly dropdown list. We used CIHI data to obtain CHD cases ascertained at birth or within 1 year of life, which was coded using the International Statistical Classification of Diseases and Related Health Problems, 10th Revision, Canadian adaptation (ICD-10-CA). The BIS CHD picklist values were matched with the CHD diagnoses in the CIHI data using the ICD-10-CA manual. Please refer to the CHD definitions in online supplemental appendix B.

\section{Covariates}

Next, we linked the dataset to the BIS aggregate pregnancy data to obtain information including maternal age at delivery, conception type, pre-pregnancy body mass index (BMI), pre-existing health conditions including physical and mental health status, social drug intake, alcohol consumption and smoking status during pregnancy, rural or urban maternal residence and infant sex.

\section{Statistical analysis}

We first performed descriptive analyses on the distributions of demographic, maternal medical and obstetric history and behaviour factors and evaluated the patterns of distributions of the aforementioned characteristics by quintiles of the maternal neighbourhood SES indicators (median household income and education level) at a DA level. Then, we conducted multivariable logistic regression models to evaluate interrelationships between the maternal neighbourhood household income, education level, maternal race and CHD after accounting for covariates including maternal age at birth, ART, obesity, preexisting health conditions including physical and mental health status, substance use during pregnancy, rural or urban maternal residence and infant's sex. Since the variables of obesity (derived variable from BMI) and race had more than $10 \%$ of values either missing or unknown, we categorised missing values into a separate non-reference level. We excluded several potential confounders including maternal parity, folic acid consumption and previous caesarean section since the OR changes of these variables were less than $10 \%$ in the multivariable regression models. ${ }^{26}$ Since CHD is a rare outcome $(<10 \%)$, ORs were used to estimate risk ratios in this study. Sensitivity analysis was performed to evaluate associations between SES, race and severe or single ventricle CHD in multivariable logistic regression models. All data linkages and analysis were performed using SAS V.9.4 (SAS Institute).

\section{Patient involvement}

Patients and their families were not involved in the research question, study design, the outcome measures, and analysis and reporting. We used registry, administrative and census data to conduct this study.

\section{RESULTS}

Among the cohort of 804292 singletons, we identified 9731 (1.21\%) infants with CHD; $3231(0.40 \%)$ cases were severe CHD and 532 cases were single ventricle CHD.

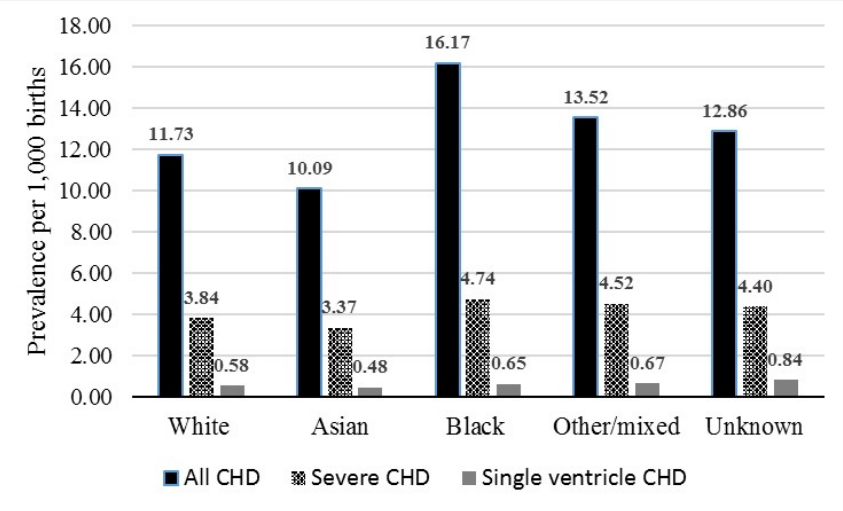

Figure 1 CHD prevalence by race. 'Unknown' group in race represents non-prenatal-screening population.

Figure 1 shows overall CHD, severe CHD and single ventricle CHD prevalence by race. Both the overall and severe CHD prevalence rates were highest among the Black group and lowest among the Asian group, while the single ventricle CHD prevalence rate was highest among the Unknown group and lowest among the Asian group.

Tables 1-3 present the distributions of demographic characteristics and medical history by the pregnant person's median household income quintiles, education level quintiles and race, respectively. Tables 1 and 2 show that the mean maternal BMI and the percentage of pregnant individuals living in the neighbourhoods who had obesity decreased from Q1 neighbourhoods to Q5 neighbourhoods. The proportion of pregnant individuals who used tobacco, social drugs or alcohol during pregnancy also demonstrated a decreasing trend from Q1 to Q5 neighbourhoods by maternal education level. The percentage of mothers with mental health conditions, or medical and obstetrical conditions were more prevalent among neighbourhoods with a lower education level. The Cochran-Armitage test showed the statistical significance of these trends $(p<0.0001)$. Table 3 shows that the percentage of pregnant individuals who had obesity prior to pregnancy was highest among the black group (25.94\%) and lowest among the Asian group (8.09\%). The percentage of people who used tobacco, social drugs or alcohol during pregnancy was highest among the white group (13.25\%) and lowest among the Asian group (1.92\%).The percentages of pregnant individuals who had mental health conditions and a history of maternal and health conditions was highest among the white group and lowest among the Asian group. Online supplemental appendix $\mathrm{C}$ table 1 shows the distribution of maternal household income and education level at a DA level by maternal race. The percentage of pregnant individuals who resided in the poorest neighbourhoods was highest among the black group (38.4\%) and lowest among the white group $(17.5 \%)$. The percentage of pregnant individuals who resided in the least educated neighbourhoods was highest among the unknown (nonprenatal-screening) group (24.2\%) and lowest among the Asian group (2.9\%). 


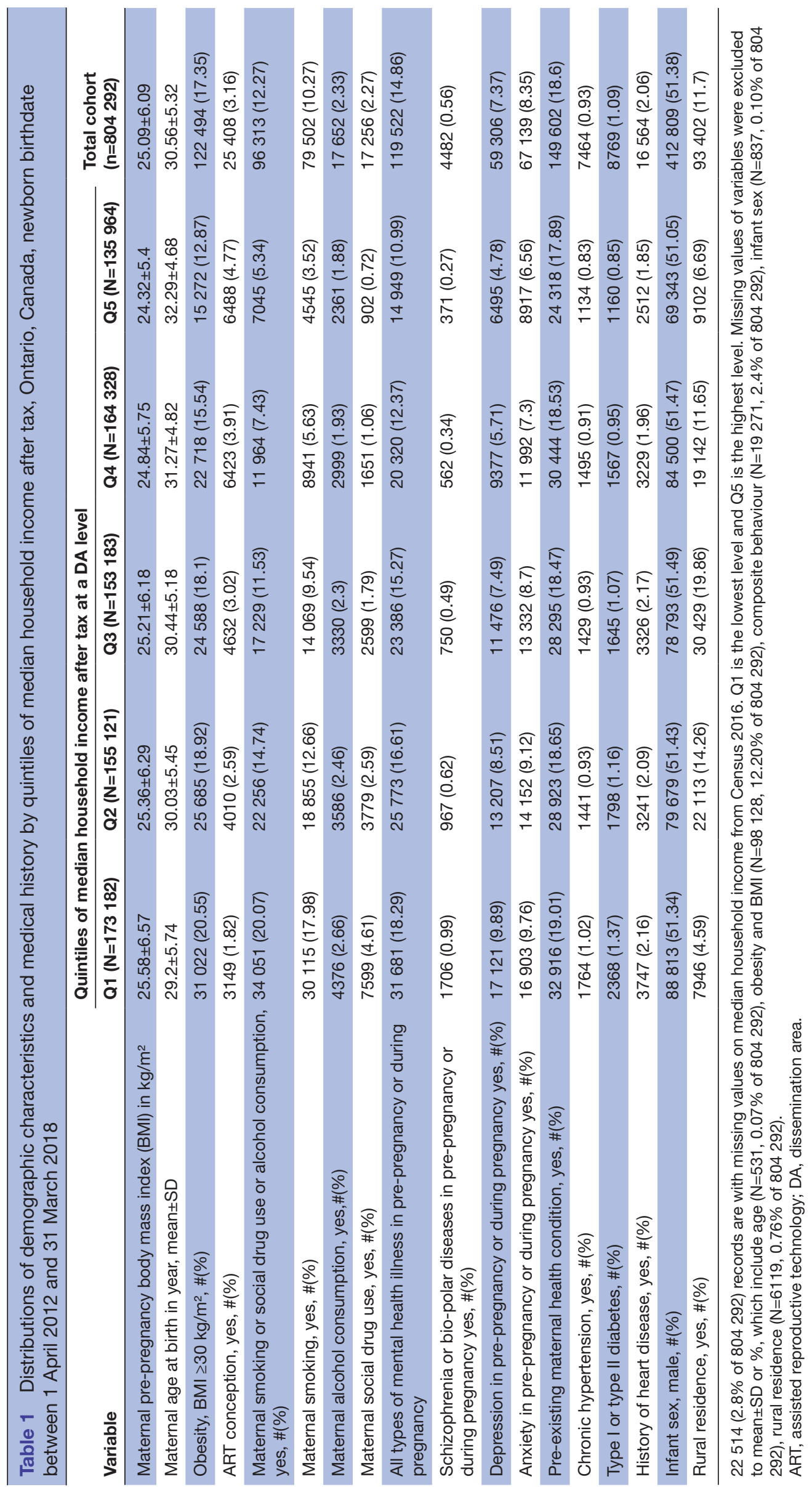




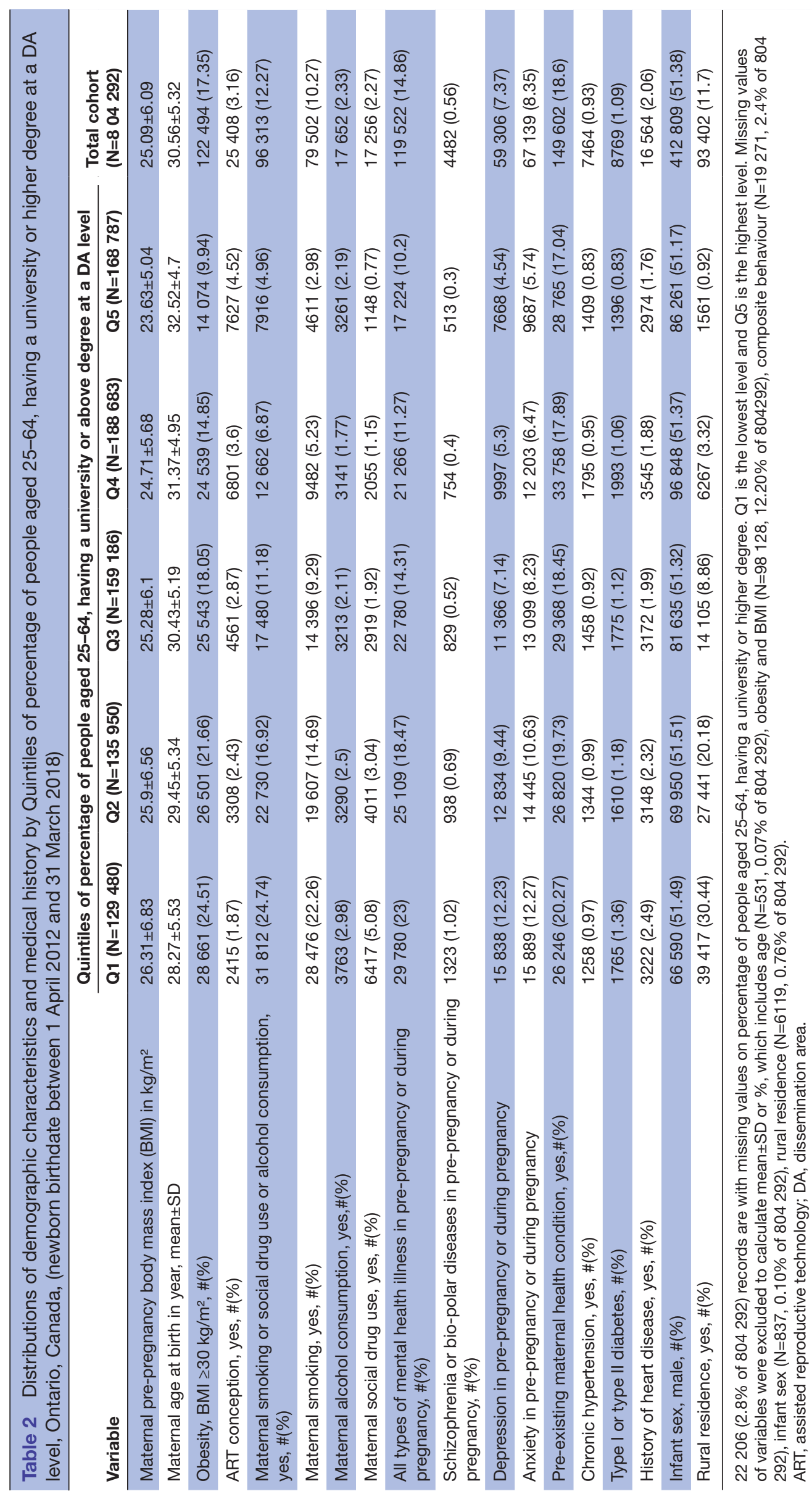




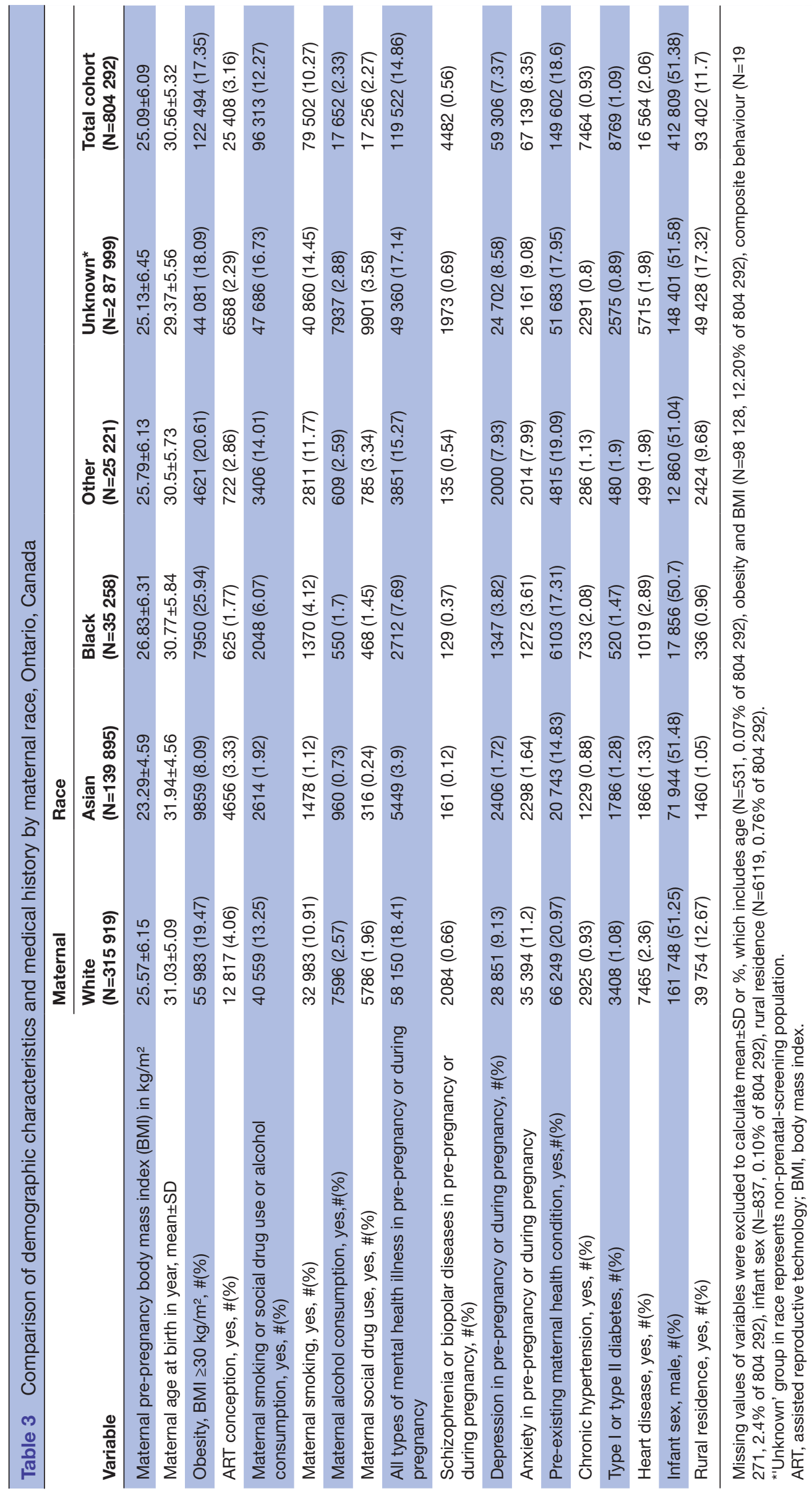


Table 4 Associations between household income and education and race to the risk of developing $\mathrm{CHD}$

\begin{tabular}{|c|c|c|}
\hline Variable & Crude OR & Adjusted OR \\
\hline \multicolumn{3}{|c|}{ Median household income after tax at a DA level } \\
\hline 1 (lowest) & $1.36(1.27-1.46)$ & $1 \cdot 15(1.06-1.24)$ \\
\hline 2 & $1 \cdot 18(1.1-1.26)$ & $1.03(0.95-1.11)$ \\
\hline 3 & $1 \cdot 11(1.03-1.19)$ & $99(0.92-1.07)$ \\
\hline 4 & $1 \cdot 10(1.03-1.18)$ & $1.04(0.96-1.12)$ \\
\hline 5 (highest) & Reference & Reference \\
\hline \multicolumn{3}{|c|}{ Percentage of people aged 25-64 had a degree of university or higher at a DA leve } \\
\hline 1 (lowest) & $1.45(1.35-1.55)$ & $126(1.16-1.36)$ \\
\hline 2 & $1.31(1.22-1.4)$ & $1.20(1.11-1.29)$ \\
\hline 3 & $1.25(1.17-1.34)$ & $1.20(1.12-1.29)$ \\
\hline 4 & $1.11(1.04-1.18)$ & $1.09(1.02-1.16)$ \\
\hline 5 (highest) & Reference & Reference \\
\hline \multicolumn{3}{|l|}{ Maternal race } \\
\hline White & Reference & Reference \\
\hline Asian & $83(0.78-0.88)$ & $97(0.91-1.04)$ \\
\hline Black & $136(1.24-1.5)$ & $1 \cdot 40(1.27-1.54)$ \\
\hline Mix/other & $1 \cdot 14(1.01-1.28)$ & $1 \cdot 14(1.02-1.28)$ \\
\hline $\begin{array}{l}\text { Unknown (non-prenatal-screening } \\
\text { group) }\end{array}$ & $1.07(1.02-1.13)$ & $1.08(1.03-1.13)$ \\
\hline \multicolumn{3}{|l|}{ Maternal age at birth } \\
\hline$<30$ years & Reference & Reference \\
\hline $30-34$ years & $93(0.89-0.98)$ & $1.02(0.97-1.07)$ \\
\hline$\geq 35$ years & $1.22(1.16-1.29)$ & $1.31(1.24-1.38)$ \\
\hline \multicolumn{3}{|l|}{ Obesity } \\
\hline Yes & $1 \cdot 4(1.33-1.47)$ & $1.23(1.16-1.3)$ \\
\hline No & Reference & Reference \\
\hline Missing & $1 \cdot 1(1.03-1.18)$ & $1 \cdot 12(1.05-1.2)$ \\
\hline \multicolumn{3}{|l|}{ ART derived pregnancy } \\
\hline Yes & $1.26(1.14-1.4)$ & $1 \cdot 16(1.05-1.3)$ \\
\hline No & Reference & Reference \\
\hline \multicolumn{3}{|c|}{ Smoking, alcohol or drug use during pregnancy } \\
\hline Yes & $1.46(1.39-1.55)$ & $1.29(1.21-1.37)$ \\
\hline No & Reference & Reference \\
\hline \multicolumn{3}{|l|}{ Mental health condition } \\
\hline Yes & $1.45(1.38-1.53)$ & $1.22(1.16-1.29)$ \\
\hline No & Reference & Reference \\
\hline \multicolumn{3}{|l|}{ Prematernal health condition } \\
\hline Yes & $1.85(1.77-1.94)$ & $1 \cdot 73(1.65-1.81)$ \\
\hline No & Reference & Reference \\
\hline \multicolumn{3}{|l|}{ Infant sex } \\
\hline Male & $1 \cdot 10(1.06-1.15)$ & $1 \cdot 10(1.06-1.15)$ \\
\hline Female & Reference & Reference \\
\hline \multicolumn{3}{|l|}{ Residence in rural area } \\
\hline Yes & $1 \cdot 12(1.05-1.19)$ & $1.04(0.97-1.12)$ \\
\hline No & Reference & Reference \\
\hline
\end{tabular}

Education: Percentage of people aged 25-64 who had a degree of university or higher at a DA level. All variables were in one multivariable logistic regression model to calculate adjusted ORs. Interaction between median household income and race on $\mathrm{CHD}$ was 0.06 . Interaction between education and race on CHD was 0.72 . There were 86152 missing values for obesity.

ART, assisted reproductive technology; $\mathrm{CHD}$, congenital heart disease; DA, dissemination area.

The interaction between median household income and race on CHD was close to statistical significance $(\mathrm{p}=0.06)$. Table 4 shows the associations between maternal neighbourhood household income, neighbourhood education level and mother's race while adjusting for covariates. Compared with infants whose mothers lived in the highest median household income neighbourhoods, infants whose mothers lived in the lowest median income neighbourhoods had a higher likelihood of having CHD (adjusted OR 1.15, 95\% CI 1.06 to 1.24). Compared with infants whose mothers lived in neighbourhoods with higher levels of postsecondary education, those infants from neighbourhoods with lower education levels had a higher chance of developing CHD (adjusted OR 1.26, 95\% CI 1.16 to 1.36). Compared with the white pregnant individuals, black pregnant individuals had higher odds of giving birth to a child with CHD (adjusted OR 1.40, $95 \%$ CI 1.27 to 1.54 ). Compared with female infants, male infants had higher odds of developing CHD (adjusted OR $1.10,95 \%$ CI 1.06 to 1.15 ).

Since the interaction between median household income and race on CHD was close to statistical significance, we performed further multivariable analysis stratified by race groups. The results of the associations between household income and CHD were similar among white (online supplemental appendix $\mathrm{C}$ table 2) and Asian pregnant individuals (online supplemental appendix C table 3). Compared with infants whose mothers lived in the highest median household income neighbourhoods, adjusted ORs of infants whose mothers lived in the lowest median income neighbourhoods were 1.15 (95\% CI 1.01 to 1.30) (white) (online supplemental appendix $\mathrm{C}$ table 2), 1.12 (95\% CI 0.94 to 1.34 ) (Asian) (online supplemental appendix C table 3), and 1.73 (95\% CI 1.16 to 2.56) (black) pregnant individuals (online supplemental appendix C table 4).

Sensitivity analyses in online supplemental appendix C table 5 and 6 show the crude ORs and adjusted ORs between maternal median household income, education level and race and severe CHD or single ventricle CHD. There was no significant difference between race groups on CHD.

\section{DISCUSSION}

Overall, severe and single ventricle CHD prevalence rates varied by race. Infants from communities with lower median household income and lower education level had a higher likelihood of developing CHD after adjusting for potential confounders. No statistically significant difference was found in the risk of CHD in children born to Asian individuals compared with White individuals. However, there was a higher likelihood of CHD in children born to black individuals compared with white individuals.

After taking account of maternal health conditions and behavioural factors in the multivariable regression models, we still detected the effects of maternal income and education level on CHD among infants. The impact of education level on CHD was greater than that of household income on CHD. The only association 
between household income and CHD was found when the comparison was conducted between infants whose mothers lived in the highest income neighbourhoods (Q5) and infants whose mothers lived in the lowest income neighbourhoods $(\mathrm{Q} 1)$. On the other hand, associations between education level and CHD were found across all quintile groups. Additionally, the strength of association decreased from lower educated neighbourhoods to higher educated neighbourhoods. These findings are consistent with another Canadian study regarding adverse birth outcomes by income and education. ${ }^{27}$

The impact of household income on birth outcomes can be related to environmental factors such as quality of nutrition or exposure to environmental toxins. ${ }^{10}{ }^{28} \mathrm{In}$ addition, poorer financial conditions may elevate stress levels, which may lead to an increase of psychosocial impact on the risk of CHD. ${ }^{29}$ Furthermore, lower education level may be a limitation in maintaining a healthy lifestyle, which we were not able to measure in this study due to data limitations. ${ }^{30}$ Although education level is usually positively related with household income, we found the positive impact of education level was more profound when both household income and education variables were adjusted in one multivariable model. A possible explanation for this finding is that Canada has a universal healthcare system which may reduce some of the financial burden. ${ }^{31}$ On the other hand, education level may play a more important role, as education level may impact the ability to achieve a healthy lifestyle and take precautions to prevent CHD and other adverse health outcomes. ${ }^{30}$

Similar to previous studies, we found evidence of racial variation in the overall prevalence of CHD. ${ }^{13} 14$ The study conducted in the UK found that the overall CHD incidence rates among all non-white children were significantly higher than those in the White group. ${ }^{13}$ In addition, non-white children tended to live in more disadvantaged environments. ${ }^{13}$ In our study, the overall CHD prevalence was the lowest among the infants born to Asian individuals, while the highest CHD rate was found among infants born to black individuals. In our study, there was a higher percentage of non-white pregnant individuals who lived in the poorest neighbourhoods; specifically, the percentage of black pregnant individuals living in the poorest neighbourhoods was more than double the percentage of white pregnant individuals living in the poorest neighbourhoods. Interestingly, the percentage of non-white individuals (black, Asian, mixed or other) living in the least educated neighbourhoods were all lower than the percentage of white people. These findings suggest that the relationships between racial groups and SES are complex in Canada, probably partially due to the heterogeneity of the non-white group. Unlike the USA, most racialised people in Canada are newcomers who tend to have postsecondary education before immigrating to Canada. ${ }^{32}{ }^{33}$ Furthermore, newcomers to Canada may have better health status than those in the general population from their countries of origin. This 'healthy immigrant' effect may be due to the Canadian government's immigration policies. ${ }^{34}$ In addition, newcomers to Canada may have lower rates of substance use and higher rates of health preventative activities and diet. ${ }^{29} 34$

Among black pregnant people, we detected the highest CHD rate for all racial groups. In the multivariable analysis, we found that compared with white pregnant people, black pregnant people had a higher likelihood of giving birth to a child with CHD, after adjusting for household income, education level and other covariates. The reasons for the association between race and CHD remain unknown and require further study.

Our results also indicate that there was a potential interaction of household income and race on CHD. When conducting stratification analysis by race, the magnitude of effect of maternal household income on CHD among black pregnant people was greater compared with other races. This finding suggests that household income may have greater impact on CHD among Black people than that in other racial groups. However, in the sensitivity analysis of associations between race, SES and the outcomes of severe and single ventricle CHD, the odds of CHD among infants whose mothers were black did not differ from white mothers (online supplemental appendix C tables 5 and 6 ).

This study had several strengths. To our knowledge, this was the first study to examine the complex relationships between community-level household income and education level, the pregnant person's race and CHD after taking into account confounders present in the Canadian context. Another strength is the large sample size, which improved the precision of the study results. Furthermore, the CHD cases were ascertained by linking multiple data sources including those identified in prenatal, postnatal or birth records and those identified up to 1 year of infancy. Finally, since our cohort included the entire birth population in Ontario, the findings of this study can be generalised to all of Canada.

There were several limitations of this study. First, due to data limitations, we used pregnant persons' residential neighbourhood median household income and education level to estimate the individual family's household income and the mother's education level, respectively, which creates the potential for misclassification bias. In addition, adjusting for the neighbourhood SES levels in multivariable regression models could lead to residual confounding bias. In Canada, neighbourhood SES factors are based on the DA level (a small geographic area) and have been considered as acceptable proxies of individual-level maternal SES factors. ${ }^{27}$ Second, all CHD records were derived from administrative data without our specific study design and variables in mind, which could have resulted in misclassification of CHD outcome. Third, all racial information was derived from the prenatal screening follow-up data in the BIS, in which $35 \%$ of pregnant people were categorised as 'Unknown', which represents the non-prenatal screening population. The heterogeneity of this group may have potentially impacted our results. Another limitation of our data is 
that all racial information was based on screening requisitions completed by heath care providers asking patients to self-identify or basing the data entered on their own judgement (personal communications with prenatal screening experts). This may have led to inconsistencies in racial classification. Furthermore, due to data limitations, we were not able to differentiate people from South Asia, West Asia and Southeast Asia. Future studies should focus on improving CHD ascertainment, as well as use a systemic and respectful approach to race and ethnicity self-determination and data collection. Lastly, variation in newcomer status (recent immigrants, refugee status and years of immigration) may potentially impact the results.

\section{CONCLUSIONS}

The findings of this study suggest that there are inequities in CHD burden by maternal SES and race in Ontario, Canada. CHD surveillance and interventions should be targeted towards vulnerable groups. The results of this study could have important implications for health policy to minimise the equity gap and reduce the burden of disease in populations at risk. Further investigation is needed to examine racial variation in CHD using more detailed racial data and increased sample size to examine the relationships between SES, race and severe and single ventricle CHD.

\section{Author affiliations}

'Better Outcomes Registry \& Network (BORN) Ontario, Children's Hospital of Eastern Ontario (CHEO) Research Institute, Ottawa, Ontario, Canada

${ }^{2}$ School of Epidemiology and Public Health, Faculty of Medicine, University of Ottawa, Ottawa, Ontario, Canada

${ }^{3}$ Department of Public Health Sciences, Queen's University, Kingston, Ontario, Canada

${ }^{4}$ School of Nursing, University of Ottawa, Ottawa, Ontario, Canada

${ }^{5}$ OMNI Research Group, Ottawa Hospital Research Institute, Ottawa, Ontario, Canada ${ }^{6}$ Department of Obstetrics \& Gynecology, Faculty of Medicine, University of Ottawa, Ottawa, Ontario, Canada

${ }^{7}$ Department of Pediatrics, Children's Hospital of Eastern Ontario (CHEO), Ottawa, Ontario, Canada

${ }^{8}$ Department of Pediatrics, Faculty of Medicine, University of Ottawa, Ottawa, Ontario, Canada

${ }^{9}$ Department of Obstetrics and Gynaecology, Sinai Health System, Toronto, Ontario, Canada

${ }^{10}$ Department of Obstetrics and Gynaecology, University of Toronto, Toronto, Ontario, Canada

${ }^{11}$ Clinical Epidemiology Program, Ottawa Hospital Research Institute, Ottawa, Ontario, Canada

Acknowledgements We thank all BORN staff, especially Dr. Lise Bisnaire, Ms. Shelley Dougan, Mr. lan Joiner and Ms. Merryn Douglas for their great support of this project; Ms. Catherine Riddell and Cathy Yang for their excellent comments for SAS code and analysis results review and Drs Tianhua Huang and Mary Guo for their comments on data elements in the BIS. We also thank $\mathrm{CIHI}$ for providing the CIHI-DAD data to BORN.

Contributors QM: project development, data management and analysis, manuscript writing and editing. QM is responsible for the overall content as the guarantor. SD, SW, JL and MW: project development, and manuscript review and revision. CM, JR and KH: manuscript review and major revision. All authors read and approved the final manuscript.

Funding This study is funded by a Canadian Institutes of Health Research (ClHR) Early Career Investigator Award in Maternal, Reproductive, Child and Youth Health
(CIHR Institute of Circulatory and Respiratory Health). The funding partner is BORN Ontario.

Disclaimer We acknowledge that each individual has the right to determine their own preferred gender, however, for the purpose of this study, the term 'maternal' refers to their biological sex. Parts of this material are based on data and information compiled and provided by $\mathrm{ClHI}$. However, the analyses, conclusions, opinions and statements expressed herein are those of the author(s), and not necessarily $\mathrm{CIHI}$.

Competing interests None declared.

Patient consent for publication Not applicable.

Ethics approval This study was approved by the Research Ethics Board boards from the Children's Hospital of Eastern Ontario and the Ottawa Health Science Network (REB protocol number:18/01PE, File number: 20180078).

Provenance and peer review Not commissioned; externally peer reviewed.

Data availability statement No data are available. The dataset from this study is held securely by BORN Ontario and cannot be made publically available due to privacy laws and the Personal Health Information Protection Act in Ontario, Canada.

Supplemental material This content has been supplied by the author(s). It has not been vetted by BMJ Publishing Group Limited (BMJ) and may not have been peer-reviewed. Any opinions or recommendations discussed are solely those of the author(s) and are not endorsed by BMJ. BMJ disclaims all liability and responsibility arising from any reliance placed on the content. Where the content includes any translated material, BMJ does not warrant the accuracy and reliability of the translations (including but not limited to local regulations, clinical guidelines, terminology, drug names and drug dosages), and is not responsible for any error and/or omissions arising from translation and adaptation or otherwise.

Open access This is an open access article distributed in accordance with the Creative Commons Attribution Non Commercial (CC BY-NC 4.0) license, which permits others to distribute, remix, adapt, build upon this work non-commercially, and license their derivative works on different terms, provided the original work is properly cited, appropriate credit is given, any changes made indicated, and the use is non-commercial. See: http://creativecommons.org/licenses/by-nc/4.0/.

\section{ORCID iDs}

Qun Miao http://orcid.org/0000-0003-4903-8491

Sandra Dunn http://orcid.org/0000-0003-4192-7884

Shi Wu Wen http://orcid.org/0000-0002-7227-0283

Cynthia Maxwell http://orcid.org/0000-0003-4734-1251

Jessica Reszel http://orcid.org/0000-0003-1702-5629

\section{REFERENCES}

1 Hoffman JIE. The global burden of congenital heart disease : review article. Cardiovasc J Afr 2013;24:141-5. doi:10.5830/CVJA-2013-028

2 Irvine B, Luo W, León JA. Report Summary - Congenital Anomalies in Canada 2013: A Perinatal Health Surveillance Report by the Public Health Agency of Canada's Canadian Perinatal Surveillance System. Health Promotion and Chronic Disease Prevention in Canada 2015;35:21-2. doi:10.24095/hpcdp.35.1.04

3 Sayasathid J, Sukonpan K, Somboonna N. Epidemiology and Etiology of Congenital Heart Diseases. CdnIntechwebOrg [Internet], 2008. Available: http://cdn.intechweb.org/pdfs/26654.pdf

4 Liu S, Joseph KS, Luo W, et al. Effect of folic acid food fortification in Canada on congenital heart disease subtypes. Circulation 2016;134:647-55.

5 Liu X, Liu G, Wang P, et al. Prevalence of congenital heart disease and its related risk indicators among 90,796 Chinese infants aged less than 6 months in Tianjin. Int J Epidemiol 2015;44:884-93.

6 Pierpont ME, Basson CT, Benson DW. Genetic Basis for Congenital Heart Defects : Current Knowledge A Scientific Statement From the American Heart Association Congenital Cardiac Defects Committee. In: Council on cardiovascular disease in the young endorsed by the American Academy of pediatrics, 2007.

7 Feng Y, Yu D, Yang L, et al. Maternal lifestyle factors in pregnancy and congenital heart defects in offspring: review of the current evidence. Ital J Pediatr 2014;40:1-7.

8 Vrijheid M, Dolk H, Stone D, et al. Socioeconomic inequalities in risk of congenital anomaly. Arch Dis Child 2000;82:349-52. doi:10.1136/ adc.82.5.349

9 Yu D, Feng Y, Yang L, et al. Maternal socioeconomic status and the risk of congenital heart defects in offspring: a meta-analysis of 33 studies. PLoS One 2014;9:e111056-4. 
10 Miao Q, Dunn S, Wen SW, et al. Neighbourhood maternal socioeconomic status indicators and risk of congenital heart disease. BMC Pregnancy Childbirth 2021;21.

11 Sadiq M, Stümper O, Wright JG, et al. Influence of ethnic origin on the pattern of congenital heart defects in the first year of life. Br Heart J 1995;73:173-6.

12 Kucik JE, Alverson CJ, Gilboa SM, et al. Racial/Ethnic variations in the prevalence of selected major birth defects, metropolitan Atlanta, 1994-2005. Public Health Rep 2012;127:52-61.

13 Knowles RL, Ridout D, Crowe S, et al. Ethnic and socioeconomic variation in incidence of congenital heart defects. Arch Dis Child 2017;102:496-502. doi:10.1136/archdischild-2016-311143

14 Nembhard WN, Wang T, Loscalzo ML, et al. Variation in the prevalence of congenital heart defects by maternal race/ethnicity and infant sex. J Pediatr 2010;156:259-64. doi:10.1016/j. jpeds.2009.07.058

15 Liston M, Carens J. Immigration and integration in Canada. Migr Glob Comp Immigr Policy Dev Ctries [Internet] 2008;207. [Epub ahead of print: Available from] https://commons.allard.ubc.ca/fac_ pubs

16 Shields J, Kelly P, Park S. Profiling immigrant poverty in Canada: a 2006 census statistical portrait. Can Rev Soc Policy 2011;65 http:// ezproxy.lib.ucalgary.ca/login?url=http://search.proquest.com/ docview/1240370650?accountid=9838\%5Cnhttp://dc8qa4cy3n search.serialssolutions.com/?ctx_ver=Z39.88-2004\&ctx_enc=info:ofi/ enc:UTF-8\&rfr_id=info:sid/ProQ\%3Acbcacomplete\&rft_val_fmt=info: ofi

17 Nuru-Jeter AM, Michaels EK, Thomas MD, et al. Relative roles of race versus socioeconomic position in studies of health inequalities: a matter of interpretation. Annu Rev Public Health 2018;39:169-88.

18 Dunn S, Lanes A, Sprague AE, et al. Data accuracy in the Ontario birth registry: a chart re-abstraction study. BMC Health Serv Res 2019;19:1001.

19 Dunn S, Sprague AE, Grimshaw JM, et al. A mixed methods evaluation of the maternal-newborn dashboard in Ontario: dashboard attributes, contextual factors, and facilitators and barriers to use: a study protocol. Implement Sci 2016;11:59. doi:10.1186/s13012-0160427-1

20 Miao Q, Fell DB, Dunn S, et al. Agreement assessment of key maternal and newborn data elements between birth registry and clinical administrative Hospital databases in Ontario, Canada. Arch Gynecol Obstet 2019;300:135-43.
21 Dunn S, Bottomley J, Ali A, et al. 2008 Niday perinatal database quality audit: report of a quality assurance project. Chronic Dis Inj Can 2011;32:32-42.

22 Dunn S, Sprague AE, Fell DB, et al. The use of a quality indicator to reduce elective repeat caesarean section for low-risk women before 39 weeks' gestation: the eastern Ontario experience. J Obstet Gynaecol Can 2013;35:306-16.

23 ClHI. Dad data elements 2015-2016, 2016. Available: https://secure. cihi.ca/estore/productSeries.htm?pc=PCC189\&_ga=2.107224642. 115153162.1540238008-2019196711.1518113758 [Accessed 22 Oct 2018].

24 Statistics Canada. Postal code conversion file plus (PCCF+) version 7b, 2017. Available: https://www150.statcan.gc.ca/n1/en/catalogue/ 82F0086X [Accessed 15 Dec 2020].

25 Hayeems RZ, Campitelli M, Ma X, et al. Rates of prenatal screening across health care regions in Ontario, Canada: a retrospective cohort study. CMAJ Open 2015;3:E236-43.

26 Rothman KJ, Timothy L. Lash associate Professor SG. modern epidemiology. In: Wolters Kluwer. 3 edn, 2012.

27 Luo Z-C, Wilkins R, Kramer MS. Effect of neighbourhood income and maternal education on birth outcomes: a population-based study. Can Med Assoc J 2006;174:1415-20.

28 Miao Q, Chen D, Buzzelli M, et al. Environmental equity research: review with focus on outdoor air pollution research methods and analytic tools. Arch Environ Occup Health 2015;70:47-55.

29 Kučienė R, Dulskienė V, Kučienė R. Maternal socioeconomic and lifestyle factors during pregnancy and the risk of congenital heart defects. Medicina 2009;45:904.

30 Pampel FC, Krueger PM, Denney JT. Socioeconomic disparities in health behaviors. Annu Rev Sociol 2010;36:349-70. doi:10.1146/ annurev.soc.012809.102529

31 Baird KE. The financial burden of out-of-pocket expenses in the United States and Canada: how different is the United States? SAGE Open Med 2016;4:205031211562379.

32 Statitics Canada. Education in Canada: key results from the 2016 census, 2017. Available: https://www150.statcan.gc.ca/n1/en/dailyquotidien/171129/dq171129a-eng.pdf?st=Z0Q5732V

33 Lu FH Y. Over-education among University-educated immigrants in Canada and the United States, 2019. Available: https://www150. statcan.gc.ca/n1/pub/11f0019m/11f0019m2019022-eng.htm

34 Riosmena F, Kuhn R, Jochem WC. Explaining the immigrant health advantage: self-selection and protection in health-related factors among five major National-Origin immigrant groups in the United States. Demography 2017;54:175-200. 